\title{
Patterns of warfarin use and subsequent outcomes in atrial fibrillation in primary care practices
}

\author{
Edward Ewen' \\ Zugui Zhang' \\ Teresa A Simon ${ }^{2}$ \\ Paul Kolm' \\ Xianchen $\mathrm{Liu}^{3,4}$ \\ William S Weintraub' \\ 'Christiana Care Health System, \\ Newark, DE, USA; ${ }^{2}$ Bristol-Myers \\ Squibb, Princeton, NJ, USA; ${ }^{3}$ Indiana \\ University School of Medicine, \\ Indianapolis, IN, USA; ${ }^{4}$ Pfizer, \\ Groton, CT, USA
}

This article was published in the following Dove Press journal:

Vascular Health and Risk Management

18 October 2012

Number of times this article has been viewed

Background: Warfarin is recommended for stroke prevention in high-risk patients with atrial fibrillation. However, it is often underutilized and inadequately managed in actual clinical practice.

Objectives: To examine the patterns of warfarin use and their relationship with stroke and bleeding in atrial fibrillation patients in community-based primary care practices.

Design: Retrospective longitudinal cohort study.

Participants: A total of 1141 atrial fibrillation patients were selected from 17 primary care practices with a shared electronic medical record and characterized by stroke risk, potential barriers to anticoagulation, and comorbid conditions.

Main measures: Duration and number of warfarin exposures, interruptions in warfarin exposure $>45$ days, stroke, and bleeding events.

Results: Among 1141 patients with a mean age of 70 years (standard deviation 13.3) and mean follow-up of 3.4 years (standard deviation 3.0), 764 (67\%) were treated with warfarin. Warfarin was discontinued within 1 year in 194 (25.4\%), and $349(45.7 \%)$ remained on warfarin at the end of follow-up. Interruptions in warfarin use were common, occurring in 32.6\% (249 of 764) of patients. Those with two or more interruptions were younger and at lower baseline stroke risk when compared to those with no interruptions. There were 76 first strokes and 73 first-bleeding events in the follow-up period. When adjusted for baseline stroke risk, time to warfarin start, and total exposure time, two or more interruptions in warfarin use was associated with an increased risk of stroke (relative risk, 2.29; 95\% confidence interval: 1.29-4.07). There was no significant association between warfarin interruptions and bleeding events.

Conclusion: Warfarin was underutilized in a substantial portion of eligible atrial fibrillation patients in these community-based practices. In addition, prolonged interruptions in anticoagulation were common in this population, and multiple interruptions were associated with over twice the risk of stroke when compared to those treated continuously.

Keywords: cardiovascular disease, primary care, quality assessment, outcomes

\section{Introduction}

Atrial fibrillation is the most common sustained cardiac rhythm disorder and represents a growing health problem in the United States. ${ }^{1}$ An estimated 6.1 million persons in the US are currently affected, and this number is projected to reach as high as 12 to 16 million by $2050 .^{2}$ In addition, atrial fibrillation is associated with significant morbidity and mortality, including increased risk of stroke, ${ }^{3}$ heart failure, ${ }^{4}$ and premature death. ${ }^{5}$ The annual risk of stroke in patients with nonvalvular atrial fibrillation when not anticoagulated is $3 \%-5 \%$, and atrial fibrillation is thought responsible for $15 \%$ of all thromboembolic strokes. ${ }^{3}$
Correspondence: Edward Ewen Department of Medicine,

Ammon Education Building, Suite 2E70

4755, Ogletown-Stanton Rd, Newark, DE 19718, USA

Tel + I 3024284672

Fax +I 3024282569

Email eewen@christianacare.org 
Multiple randomized clinical trials have established the effectiveness of warfarin in reducing the risk of stroke in atrial fibrillation patients by approximately two-thirds, ${ }^{6-10}$ and published guidelines for stroke prevention in these patients recommend warfarin therapy for those at moderate to increased risk of stroke. ${ }^{11}$ Maximizing the potential benefits while reducing the risk of bleeding on warfarin therapy, however, requires careful titration of dose to maintain anticoagulation intensity within a narrow international normalized ratio (INR) range between 2 and $3 .{ }^{12-14}$ Despite this evidence, in actual clinical practice, many patients who qualify for oral anticoagulation do not receive it, ${ }^{15}$ and among those who do, only half of their time is spent in therapeutic range, ${ }^{16-22}$ and one in four discontinue warfarin within 1 year of starting use. ${ }^{23}$ Furthermore, when compared to those treated in anticoagulation clinics, those followed in community practices spend on average $11 \%$ less time in therapeutic range. ${ }^{24}$

Few studies have examined patterns of warfarin use in terms of discontinuations and interruptions, and none have yet described the relationship of these patterns to stroke and bleeding outcomes. ${ }^{16,23}$ We examined warfarin use and interruptions, the quality of anticoagulation, and their relationship with subsequent stroke and bleeding events in nonvalvular atrial fibrillation patients in community-based primary care practices.

\section{Methods}

\section{Study setting and population}

We conducted a retrospective longitudinal cohort study of atrial fibrillation patients followed in one of 17 adult primary care practices at any point between January 1, 1998, and June 30, 2010. These specific general internal medicine and family medicine practices were chosen for inclusion in this study based on their use of a common office electronic medical record (EMR) over an extended period of time, and were part of a larger health care system, Christiana Care Health System (CCHS), located in northern Delaware and providing $80 \%$ of the acute care services to this region. Approximately one-third were involved in resident training, and none were dedicated anticoagulation clinics.

The initial study cohort included all patients who were 18 years or older at the time of atrial fibrillation diagnosis and had had at least one office visit following the date of diagnosis. The diagnosis of atrial fibrillation was determined by the presence of either atrial fibrillation or atrial flutter recorded by a clinician at the point of care on the office problem list (International Classification of Diseases, Ninth Revision, Clinical Modification [ICD-9-CM] codes 427.30 and 427.31). In addition, clinicians could indicate whether the atrial fibrillation was either chronic or paroxysmal at the time of diagnosis. From this cohort, we excluded patients with no office visits following the date of diagnosis, as well as those with a history of mitral or aortic valve repair or replacement, transient perioperative atrial fibrillation, or hyperthyroidism by diagnosis or treatment at any time prior to diagnosis (Appendix 1). Patients were followed from the date of diagnosis to the date of the patient's death or the study end date.

\section{Data sources}

Information on demographics, medication use, and clinical variables, including prior ischemic stroke, gastrointestinal and intracranial hemorrhage, congestive heart failure, hypertension, diabetes, alcohol abuse, cirrhosis, renal disease, cognitive dysfunction, and conditions predisposing to falls were obtained using the EMR problem list. The hospital administrative database was used to further identify episodes of stroke, heart failure, and hemorrhages occurring prior to the diagnosis of atrial fibrillation. $\mathrm{A} \mathrm{CHADS}_{2}$ strokerisk score ${ }^{25}$ was calculated for each patient at baseline and for each subsequent day of follow-up for time-dependent analysis. Identification of both office and hospital diagnoses were based on the ICD-9-CM codes assigned at discharge in the hospital or on problem entry in the office. Laboratory values, including hemoglobin, creatinine, and INR, were obtained from both the office EMR and hospital inpatient and outpatient laboratory systems. Specific data definitions for potential barriers to warfarin use and predictors of stroke and hemorrhage are included in Appendices 2 and 3. All medications prescribed in the EMR were entered in a structured (codified) manner at the point of care, including dose and instructions, facilitating identification and classification. In addition, every prescription generated recorded the date, quantity, and number of refills. The research use of these databases was approved by the CCHS institutional review board, and procedures were followed in accordance with institutional guidelines.

\section{Warfarin exposure and anticoagulation intensity}

Warfarin exposure was determined through a combination of prescription history and INR measurements. The duration of warfarin exposure was based on the start date of the prescription and the calculated number of days supply, based on the dose, quantity supplied, instructions for use, and number of refills. Because warfarin dose is often adjusted 
after a prescription is written, a 30-day grace period and a 15-day elimination or washout period was added to each prescription's calculated duration. As a result, gaps of up to 45 days between calculated days of supply were considered continuous therapy. Gaps greater than 45 days were considered continuous if there were intervening INR values at least every 45 days bridging the prescription gap. Gaps greater than 45 days without intercurrent INR values were considered warfarin interruptions if the patient subsequently restarted warfarin. Patients were then categorized as having none, one, and two or more warfarin interruptions (Figure 1). These gaps were considered discontinuations if warfarin was not restarted prior to the study end.

Once warfarin exposures were determined, we then classified these exposure periods in terms of time in therapeutic range. Simple linear interpolation between consecutive INR
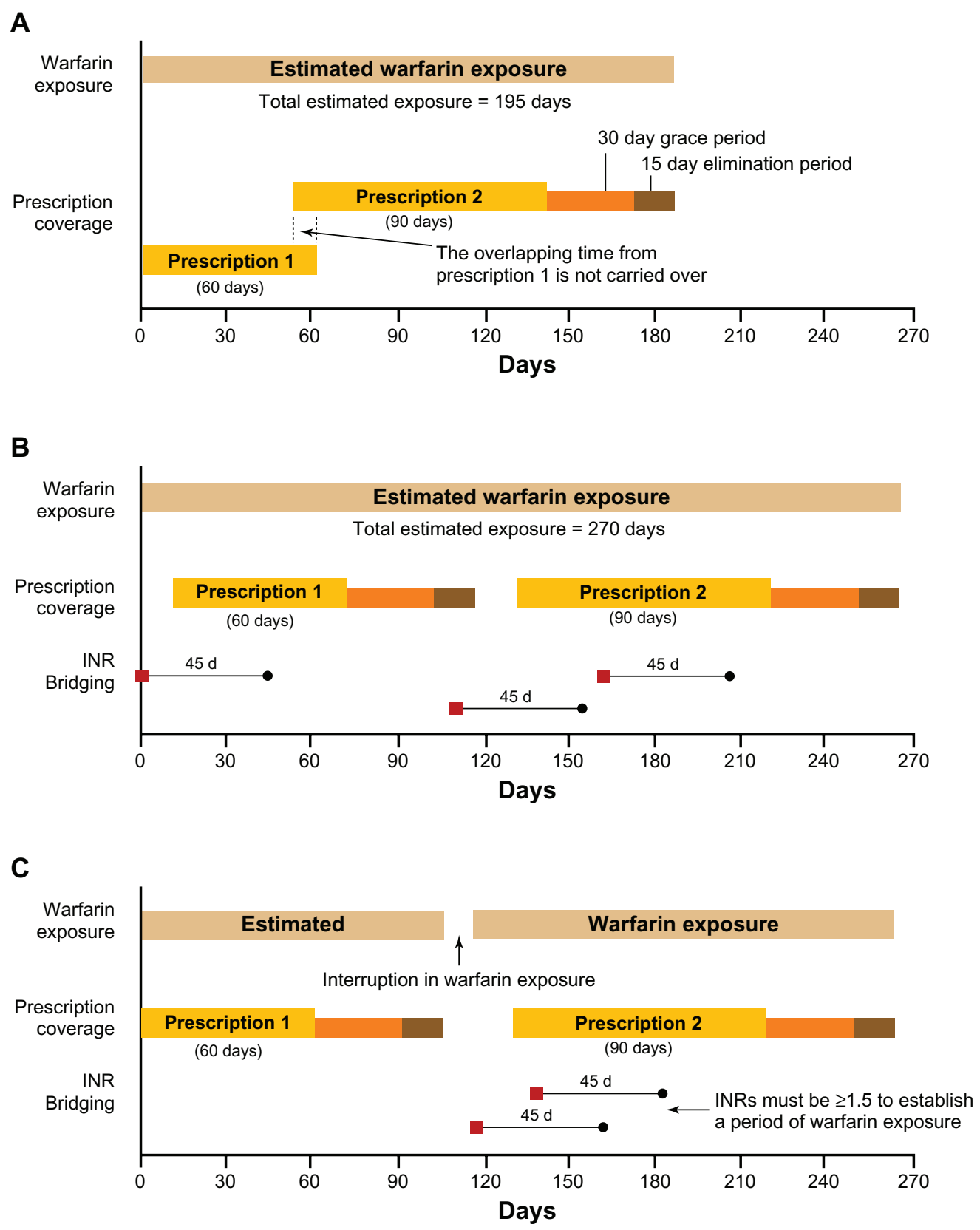

Figure I (A-C) Calculation of warfarin exposure. Three scenarios demonstrating the methods used to estimate warfarin exposure. (A) Calculation of warfarin exposure when consecutive prescription coverage periods overlap. This panel also demonstrates the application of the 30 day grace and 15 day elimination periods. (B) Warfarin exposure calculated with INR measurements bridging between periods of prescription coverage. (C) Warfarin exposure calculated based on periods of prescription coverage and INR measurements with an interruption in warfarin exposure demonstrated. Abbreviation: INR, international normalized ratio. 
values in a manner similar to that used by Rosendaal et $\mathrm{al}^{26}$ was used to classify person-time into predefined categories of therapeutic range (INR $<2$, subtherapeutic; INR 2-3, therapeutic; INR $>3$, supertherapeutic; and INR unknown). If INR values were separated by more than 45 days within a period of warfarin exposure, that time from 45 days after the preceding INR value until the next INR value was classified as unknown. The overall proportion of time in therapeutic range (TTR) was calculated for each patient, excluding the time defined as "unknown." Patients were then categorized as having their proportion of TTR as $\geq 60 \%$ or $<60 \%$.

\section{Outcomes}

Principal outcomes include the frequency of warfarin interruptions, proportion of time in therapeutic range, stroke or transient ischemic attack (TIA), and hemorrhage. Strokes and TIAs were identified using principal ICD-9 discharge diagnosis extracted from the hospital administrative database. Bleeding events were identified using a combination of primary and secondary hospital discharge diagnosis codes and office EMR problem list entries. All stroke/TIAs and bleeding events were confirmed by manual physician chart review.

\section{Analysis}

Descriptive statistics were used to summarize population characteristics overall and in the warfarin treated. Those exposed to warfarin were further categorized into those with none, one, or two or more interruptions in warfarin therapy. The chi-square statistic was used to compare proportions, and the Kruskal-Wallis test was conducted to compare means and medians.

The binary outcomes of warfarin exposure, multiple interruptions in warfarin exposure, and proportion of TTR $\geq 60 \%$ were modeled using multivariable logistic regression. Variables associated with each outcome on univariate analysis $(P<0.15)$ were included as potential predictors in each model, and results presented as odds ratios (ORs) with $95 \%$ confidence intervals (CI).

The crude incidence rates and 95\% CI of first stroke/ TIA and bleeding were calculated for each level of warfarin interruption and compared using the Kaplan-Meier method, with differences evaluated using the log-rank test. ${ }^{27}$ Because of the time-varying nature of warfarin exposure and potentially long duration of follow-up, nested case-control analyses with matching on time to event were conducted to obtain unbiased estimates of the relative risk of stroke/ TIA or bleeding related to multiple interruptions in warfarin exposure. ${ }^{28-30}$ A conditional logistic regression model was applied to perform the nested case-control analysis and results expressed as risk ratios (RRs) with 95\% CI.

\section{Results}

\section{Baseline characteristics and follow-up}

Of 121,246 patients followed in these office practices, a total of 1141 patients with atrial fibrillation met the selection criteria (Figure 1). This population accumulated 3848 person-years of time, with a mean of 3.37 years (standard deviation [SD] 2.97, median 2.37, interquartile range [IQR] 1.08-4.93) following their diagnosis of atrial fibrillation. The mean age at diagnosis was 70 years (SD 13 years); more than $68 \%$ were aged 65 and older, $48.3 \%$ were women, $12.5 \%$ were African-American, and $80.7 \%$ had a diagnosis of chronic or persistent atrial fibrillation. There was a prior history of stroke or TIA in $11.1 \%$, heart failure in $12.4 \%$, known coronary artery disease in $20.4 \%$, hypertension in $43.1 \%$, and diabetes mellitus in $15.6 \%$. There were 437 $(38.3 \%)$ patients with a $\mathrm{CHADS}_{2}$ score $\geq 2$ and considered at high risk for stroke.

\section{Warfarin exposure}

Warfarin was used at some point after diagnosis in $66.7 \%$ ( $n=764$ ) of the population. Overall, those patients receiving warfarin were older, more often diagnosed with chronic rather than paroxysmal atrial fibrillation, and followed longer than those not receiving warfarin (Table 1). Of those at high risk for stroke $\left(\mathrm{CHADS}_{2}\right.$ score $\left.\geq 2\right), 295$ (67.5\%) received warfarin at some point after diagnosis. There was no significant association between treatment with warfarin and potential barriers to warfarin use considered as a group, even in those at high risk for stroke $(P=0.36)$. When examining predictors of warfarin use (Figure 2), those with chronic atrial fibrillation (adjusted OR, 2.99; 95\% CI: 2.19-4.08), age $\geq 75$ years (OR, 1.42; 95\% CI: 1.07-1.89), AfricanAmerican (OR, 1.70; 95\% CI: 1.10-2.63), or a prior history of heart failure (OR, 1.61; 95\% CI: 1.037-2.52) were more likely to receive warfarin. Patients with significant anemia (hemoglobin $\leq 10.0 \mathrm{~g} / \mathrm{dL}$, OR, 0.67; 95\% CI: 0.48-0.93), hypertension (OR, 0.76; 95\% CI: 0.58-0.99), or a diagnosis predisposing to falls (OR, 0.71; 95\% CI: 0.51-0.99) were less likely to receive warfarin therapy $(\mathrm{c}$-statistic $=0.66)$.

During examination of the 764 warfarin-treated patients, there were 1358 patient-years of warfarin exposure during 2857 person years of follow-up time. These patients were followed for a mean of 3.74 years (median 2.78, IQR 1.26-5.57) and were treated with warfarin for a mean of 1.78 years (median 1.09, IQR 0.39-2.38). Warfarin was 
Table I Baseline characteristics by warfarin use

\begin{tabular}{|c|c|c|c|}
\hline & \multicolumn{3}{|c|}{ Warfarin exposure } \\
\hline & $\begin{array}{l}\text { Exposed } \\
(n=764)\end{array}$ & $\begin{array}{l}\text { Not exposed } \\
(n=377)\end{array}$ & $P$-value \\
\hline Chronic atrial fibrillation (\%) & $665(87)$ & $256(67.9)$ & $<0.001$ \\
\hline Age, mean $(S D)$ & $72(I 2)$ & $68(15)$ & $<0.001$ \\
\hline Age, years (\%) & & & $<0.001$ \\
\hline$<55$ & $81(10.6)$ & $91(24.1)$ & \\
\hline $55-64$ & $126(16.5)$ & $65(17.2)$ & \\
\hline $65-74$ & $212(27.7)$ & $77(20.4)$ & \\
\hline$\geq 75$ & $345(45.2)$ & 144 (38.2) & \\
\hline Women (\%) & $36 \mid(47.3)$ & $190(50.4)$ & 0.32 \\
\hline African-American (\%) & $106(13.9)$ & $37(9.8)$ & 0.05 \\
\hline \multicolumn{4}{|l|}{ Risk factors for stroke (\%)* } \\
\hline Stroke or TIA & $92(12)$ & $35(9.3)$ & 0.16 \\
\hline Heart failure & $109(14.3)$ & $33(8.8)$ & 0.008 \\
\hline Hypertension & $315(4 I .2)$ & 177 (46.9) & 0.07 \\
\hline Diabetes mellitus & $116(15.2)$ & $62(16.4)$ & 0.58 \\
\hline Coronary heart disease & $166(2 \mid .7)$ & $67(17.8)$ & 0.12 \\
\hline Peripheral vascular disease & $22(2.9)$ & $8(2.1)$ & 0.45 \\
\hline $\mathrm{CHADS}_{2}$ stroke risk score* & & & 0.05 \\
\hline 0 & $202(26.4)$ & $124(32.9)$ & \\
\hline I & $267(34.9)$ & III (29.4) & \\
\hline$\geq 2$ & $295(38.6)$ & $142(37.7)$ & \\
\hline \multicolumn{4}{|c|}{ Potential barriers to warfarin use* } \\
\hline Gastrointestinal bleeding & $48(6.3)$ & $23(6.1)$ & 0.91 \\
\hline Alcohol abuse & $35(4.6)$ & $21(5.6)$ & 0.47 \\
\hline Cirrhosis/hepatitis & $54(7.1)$ & $31(8.2)$ & 0.49 \\
\hline Cognitive dysfunction & $55(7.2)$ & $32(8.5)$ & 0.44 \\
\hline Fall risk & $129(16.9)$ & $8 I(2 I .5)$ & 0.06 \\
\hline Anemia $^{\dagger}$ & $149(19.5)$ & $94(24.9)$ & 0.04 \\
\hline CKD stages $3-5$ & $282(36.9)$ & $107(28.4)$ & 0.004 \\
\hline \multicolumn{4}{|c|}{ Other antithrombotic therapy (\%) } \\
\hline Aspirin & $352(46.1 \%)$ & $252(66.8 \%)$ & $<0.001$ \\
\hline Clopidogrel & $77(10.1 \%)$ & $3 \mathrm{I}(8.2 \%)$ & 0.31 \\
\hline Years followed (SD) & $3.74(3.06)$ & $2.63(2.63)$ & $<0.001$ \\
\hline
\end{tabular}

Notes: *Identified prior to atrial fibrillation diagnosis; themoglobin $\leq 10 \mathrm{mg} / \mathrm{dL}$. Abbreviations: SD, standard deviation; TIA, transient ischemic attack; CKD chronic kidney disease.

started at the time of diagnosis in 412 patients (53.9\%), and over $75 \%(n=580)$ were started within 180 days of atrial fibrillation diagnosis. Within 1 year, 25.4\% (194 of 764) had permanently discontinued warfarin use. At the conclusion of the follow-up period, 349 (45.7\%) of warfarin-treated patients were still using warfarin. The majority of patients had a single exposure to warfarin $(67.4 \%, \mathrm{n}=515)$, and once started, 235 (45.6\%) of these remained on warfarin for the duration of follow-up.

There were 553 interruptions in warfarin therapy occurring in 32.6\% $(\mathrm{n}=249)$ patients, with 129 patients having a single interruption and 120 having two or more interruptions in usage. These interruptions lasted a mean of 339 days (SD 499 days, median 125 days, IQR 31-430 days) and were of decreasing duration as the number of interruptions per patient

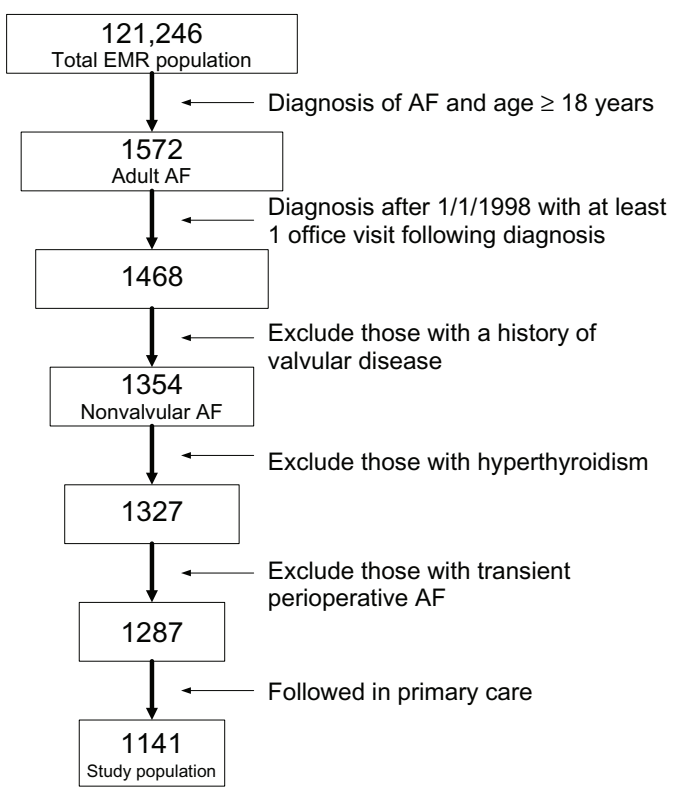

Figure 2 Population and cohort definition.

Abbreviations: EMR, elctronic medical record; AF, atrial fibrillation.

increased $(P<0.01)$. Patients with interruptions in warfarin therapy were younger, followed longer, and were at lower stroke risk than those with no interruptions in therapy, while there was no significant association between the presence of potential barriers to warfarin therapy and the frequency of interruptions (Table 2). In multivariable analysis adjusting for time to warfarin start, total years followed, and demographics (Figure 3 ), only hypertension significantly predicted freedom from interruption (OR 0.65, 95\% CI 0.44-0.96, c-statistic $=0.79)($ Figure 4$)$.

\section{Quality of anticoagulation}

In patients treated with warfarin, the majority of time spent anticoagulated was classified by our algorithm as unknown (68\%, 922 patient-years). When the therapeutic range was known, patients spent $47.3 \%$ of their time in therapeutic range (INR 2-3), $40.2 \%$ of the time below therapeutic range, and $12.5 \%$ above therapeutic range. Only $23.4 \%$ of patients spent $60 \%$ or more of their time on warfarin in therapeutic range. Age, sex, race, and stroke-risk factors were not predictive of achieving good control, and there were no significant differences in the proportion of time spent in subtherapeutic, therapeutic, and supertherapeutic ranges between those with no, a single, and multiple interruptions in warfarin use.

\section{Stroke and bleeding}

In the period following atrial fibrillation diagnosis, there were 107 strokes occurring in 76 patients. The majority of 
Table 2 Baseline characteristics by frequency of warfarin interruptions

\begin{tabular}{|c|c|c|c|c|}
\hline & \multicolumn{3}{|c|}{ Number of warfarin interruptions } & \multirow[t]{2}{*}{$P$-value } \\
\hline & $\begin{array}{l}\text { None } \\
(n=5 \mid 5)\end{array}$ & $\begin{array}{l}I \\
(n=129)\end{array}$ & $\begin{array}{l}\geq 2 \\
(n=120)\end{array}$ & \\
\hline Chronic atrial fibrillation & $446(86.6)$ & $108(83.7)$ & III (92.5) & 0.10 \\
\hline Age in years, mean (SD) & $73(1 \mathrm{I})$ & $7 \mid(\mid 3)$ & $68(12)$ & 0.002 \\
\hline Age, years $(\%)$ & & & & 0.05 \\
\hline$<55$ & $45(8.7)$ & $17(13.2)$ & $19(15.8)$ & \\
\hline $55-64$ & $80(15.5)$ & $19(14.7)$ & $27(22.5)$ & \\
\hline $65-74$ & $143(27.8)$ & $37(28.7)$ & $32(26.7)$ & \\
\hline$\geq 75$ & $247(48)$ & $56(43.4)$ & $42(35)$ & \\
\hline Women (\%) & $239(46.4)$ & $68(52.7)$ & $54(45)$ & 0.38 \\
\hline African-American (\%) & $63(12.2)$ & $20(15.5)$ & $23(19.2)$ & 0.12 \\
\hline \multicolumn{5}{|l|}{ Risk factors for stroke (\%)* } \\
\hline Stroke or TIA & $445(86.4)$ & $119(92.2)$ & $108(90)$ & 0.14 \\
\hline Heart failure & $77(15)$ & $15(11.6)$ & $17(14.2)$ & 0.63 \\
\hline Hypertension & $242(47)$ & $46(35.7)$ & $27(22.5)$ & $<0.001$ \\
\hline Diabetes mellitus & $93(18.1)$ & $17(13.2)$ & $6(5)$ & 0.001 \\
\hline Coronary heart disease & $119(23.1)$ & $23(17.8)$ & $24(20)$ & 0.38 \\
\hline Peripheral vascular disease & $14(2.7)$ & $6(4.7)$ & $2(1.7)$ & 0.35 \\
\hline $\mathrm{CHADS}_{2}$ stroke risk score & & & & $<0.001$ \\
\hline 0 & III (2I.6) & $42(32.6)$ & $49(40.8)$ & \\
\hline 1 & $178(34.6)$ & $46(35.7)$ & $43(35.8)$ & \\
\hline$\geq 2$ & $226(43.9)$ & $4 \mid(31.8)$ & $28(23.3)$ & \\
\hline \multicolumn{5}{|c|}{ Perceived barriers to warfarin Use* } \\
\hline Gastrintestinal bleeding & $31(6)$ & II (8.5) & $6(5)$ & 0.47 \\
\hline Alcohol abuse & $21(4.1)$ & $5(3.9)$ & $9(7.5)$ & 0.25 \\
\hline Cirrhosis/hepatitis & $37(7.2)$ & $8(6.2)$ & $9(7.5)$ & 0.91 \\
\hline Cognitive dysfunction & $34(6.6)$ & II (8.5) & $10(8.3)$ & 0.66 \\
\hline Fall risk & $96(18.6)$ & $18(14)$ & $15(12.5)$ & 0.17 \\
\hline Anemia $^{\dagger}$ & $108(2 \mathrm{I})$ & $23(17.8)$ & $18(15)$ & 0.29 \\
\hline CKD stages 3-5 & I8I (35.I) & $49(38)$ & $52(43.3)$ & 0.24 \\
\hline \multicolumn{5}{|c|}{ Other antithrombotic therapy (\%) } \\
\hline Aspirin & $221(42.9)$ & $69(53.5)$ & $60(50)$ & 0.06 \\
\hline Clopidogrel & $12(2.3)$ & $3(2.3)$ & I (0.8) & 0.58 \\
\hline Years followed, mean (SD) & $2.8(2.5)$ & $4.6(3.0)$ & $6.8(2.9)$ & $<0.001$ \\
\hline
\end{tabular}

Notes: *Identified prior to atrial fibrillation diagnosis; themoglobin $\leq 10 \mathrm{mg} / \mathrm{dL}$.

Abbreviations: SD, standard deviation; TIA, transient ischemic attack; CKD, chronic kidney disease.

these strokes occurred in the warfarin users ( 95 strokes in 65 patients). When focusing on first stroke events and comparing unadjusted rates, those patients with multiple interruptions in warfarin therapy had an increased incidence of stroke compared to those with no interruptions in treatment (Table 3). In nested case-control analysis adjusting for sex, race, and $\mathrm{CHADS}_{2}$ stroke risk, those with two or more warfarin interruptions were at significantly higher risk of stroke compared to those with no interruptions (RR 2.29, 95\% CI $1.29-4.07, P=0.005$ ).

There were 73 bleeding events (40 major and 33 minor) occurring after atrial fibrillation diagnosis in 64 patients. Of these events, 18 involved intracranial bleeding and 55 were due to gastrointestinal bleeding. The number of warfarin interruptions appeared to have no impact on unadjusted bleeding rates and, after multivariable adjustment using the nested case-control analysis, there were no significant differences found between groups.

\section{Discussion}

In this retrospective analysis of 1141 atrial fibrillation patients followed in these community-based primary care practices, we found significant deficiencies with both the initiation and subsequent maintenance of warfarin therapy. Nearly onethird of those at high risk for stroke CHADS $_{2}$ stroke-risk score $\geq 2$ ) never received warfarin therapy despite the absence of identified barriers to anticoagulation. When examining patterns of warfarin use, we found that while it was often 


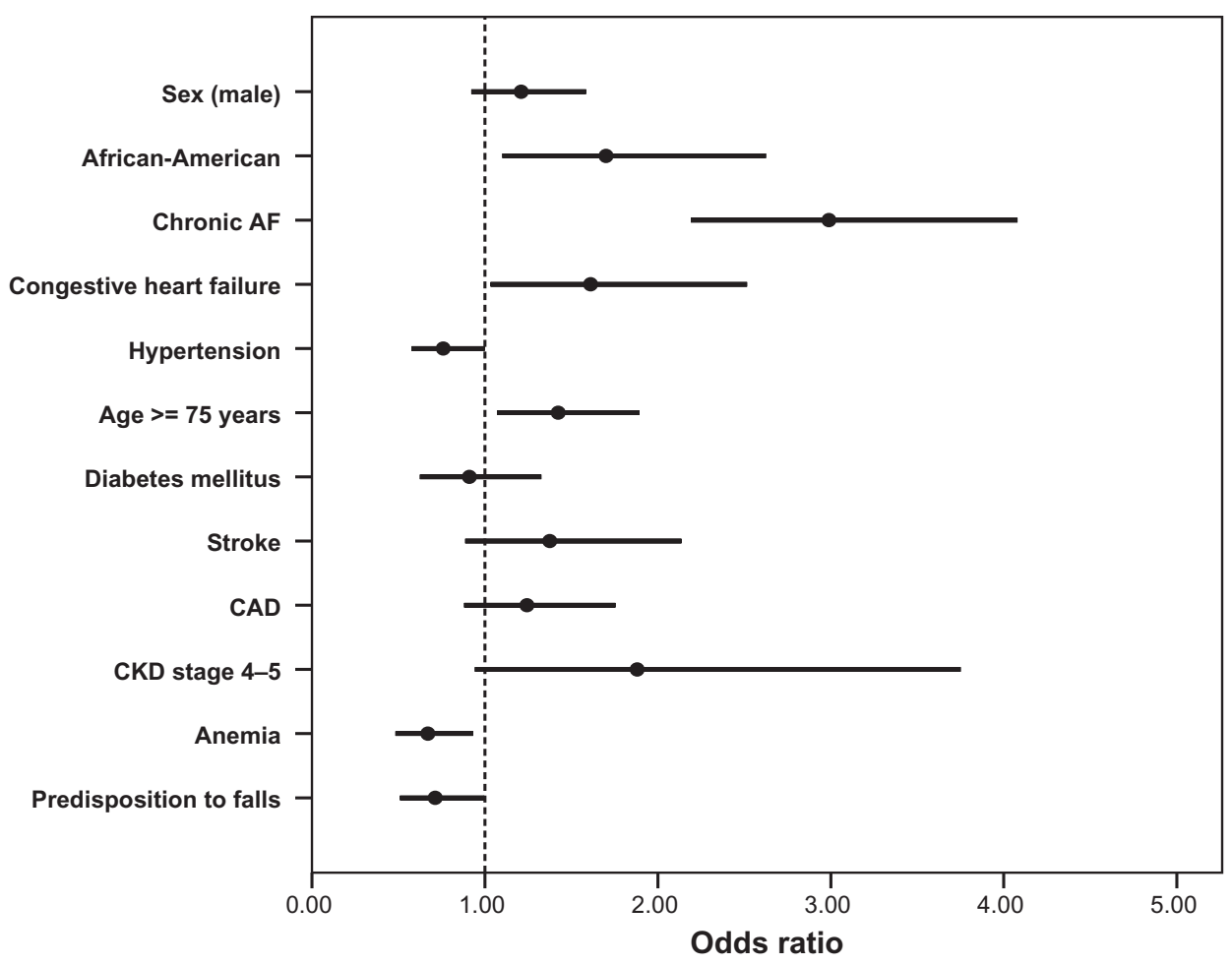

Figure 3 Forest plot of the predictors of warfarin use.

Notes: Odds ratio with $95 \%$ confidence interval. Anemia $=$ hemoglobin $\leq 10 \mathrm{mg} / \mathrm{dL}$.

Abbreviations: AF, atrial fibrillation; CAD, coronary artery disease; CKD, chronic kidney disease (MDRD stages 4-5).

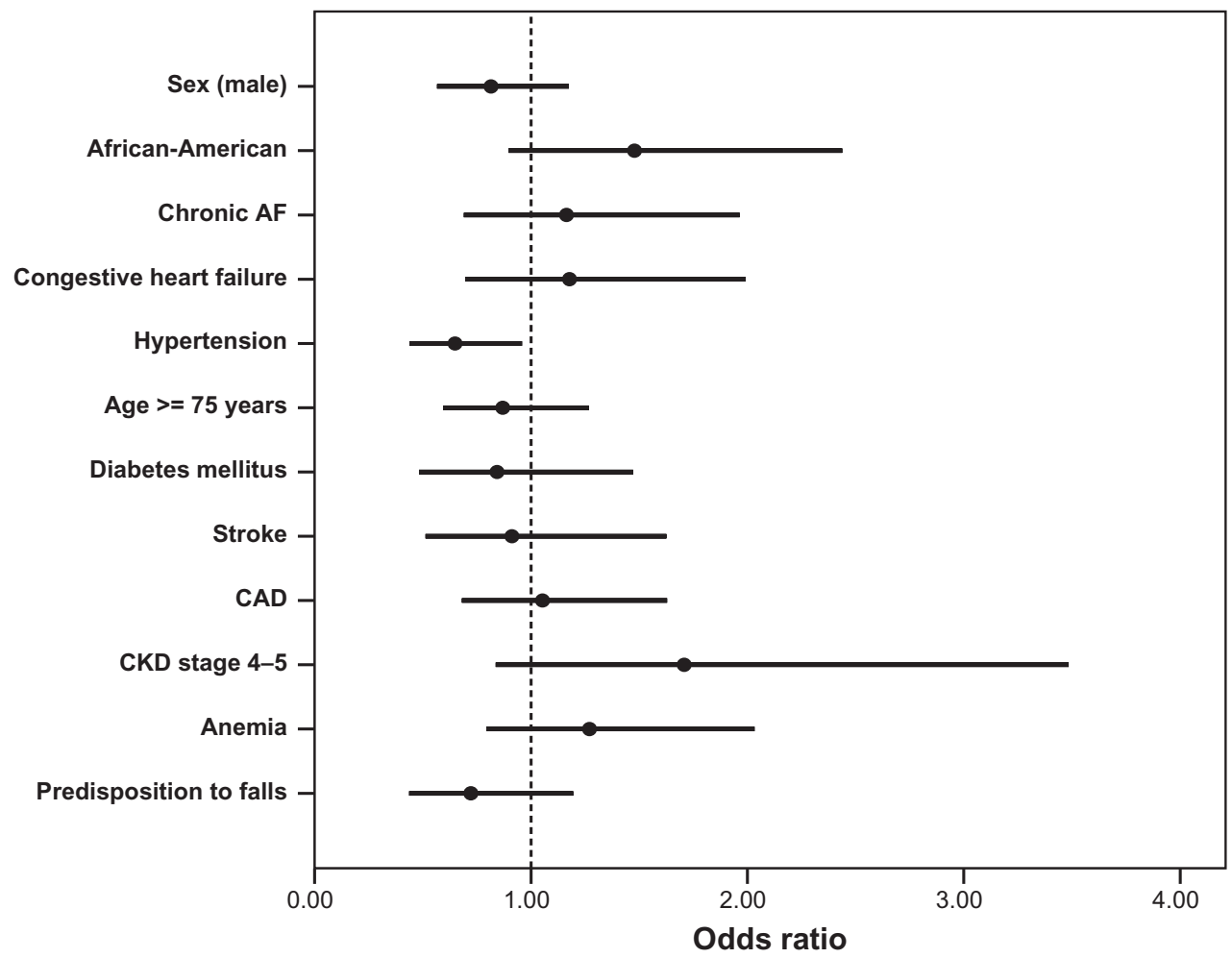

Figure 4 Forest plot of the predictors of warfarin interruptions.

Notes: Odds ratio with $95 \%$ confidence interval. Anemia = hemoglobin $\leq 10 \mathrm{mg} / \mathrm{dL}$.

Abbreviations: AF, atrial fibrillation; CAD, coronary artery disease; CKD, chronic kidney disease (MDRD stages 4-5). 
Table 3 Incidence rate of stroke and bleeding events by frequency of warfarin interruptions

\begin{tabular}{|c|c|c|c|c|}
\hline & Events, $\mathbf{n}$ & Patient-years & Incidence density \% $(95 \% \mathrm{Cl})$ & $P$-value \\
\hline Stroke/TIA & & & & 0.01 \\
\hline No interruptions & 27 & 1387 & $1.9(1.3,2.8)$ & \\
\hline One interruption & 13 & 570 & $2.3(1.2,3.9)$ & \\
\hline$\geq$ two interruptions & 25 & 702 & $3.6(2.3,5.3)$ & \\
\hline Bleeding & & & & 0.86 \\
\hline No interruptions & 27 & 1399 & $1.9(1.3,2.8)$ & \\
\hline One interruption & 10 & 583 & I.7 $(0.8,3.2)$ & \\
\hline$\geq$ two interruptions & 13 & 773 & $1.7(0.9,2.9)$ & \\
\hline
\end{tabular}

Abbreviations: $\mathrm{Cl}$, confidence interval; TIA, transient ischemic attack.

started soon after diagnosis, warfarin-treated patients spent on average less than half of their follow-up time actually taking the medication. Over $25 \%$ of patients discontinued warfarin within 1 year, and less than half of these patients remained on warfarin at the conclusion of the study period. Furthermore, interruptions in warfarin use lasting on average nearly 1 year were common, affecting nearly one-third of those treated, and multiple interruptions were associated with more than twice the risk of stroke when compared to those with no interruptions in therapy. This increased risk appears despite those with multiple interruptions being younger, having lower stroke-risk scores, and similar estimates of TTR.

We also examined the quality of anticoagulation in our population as a proportion of TTR. Because we did not interpolate INR values beyond 45 days, over two-thirds of our person-time was classified as "unknown therapeutic range." When INRs could be interpolated, we found that only $47.3 \%$ of our patients' time was spent in therapeutic range, and less than one-quarter remained in therapeutic range for $60 \%$ or more of their exposure time. A recent study of 4408 atrial fibrillation patients demonstrated an inverse relationship between the interval between INR measurements and the observed TTR, with TTR decreasing from $48 \%$ to $41 \%$ as INR measurement intervals increased from 3 to 5 weeks. ${ }^{31}$ Given that time classified as "unknown" in our analysis implies $>6$ weeks between INR measurements, it is likely that with simple linear interpolation, the TTR in our population would be somewhat lower, though still similar to that seen in other studies performed in community-based settings. ${ }^{24}$ These results highlight the significant proportion of untreated high-risk patients, the difficulty clinicians have in maintaining patients on warfarin once the decision is made to initiate anticoagulation, and the significant proportion of time patients remain unprotected from thrombotic events in actual clinical practice.

Few studies have looked specifically at interruptions or discontinuations in warfarin use and the consequences in terms of stroke and bleeding events. In one observational study of 4188 atrial fibrillation patients newly started on warfarin, over $26 \%$ discontinued within 1 year; with younger patients ( $\leq 65$ years), those with poorer anticoagulation and those at lower stroke risk $\left(\mathrm{CHADS}_{2}=0\right)$ had the greatest risk of discontinuation. ${ }^{23}$ Our 1-year discontinuation rate of $25 \%$ is similar to that seen in this and other studies where warfarin discontinuation ranges from $16 \%$ to $30 \%$ at 1 year. ${ }^{32-34}$ Our study also confirms our current understanding concerning warfarin underuse in the community setting by examining a diverse set of actual clinical practices over a decade of time. Previous community-based studies report warfarin use in high-risk atrial fibrillation patients ranging from $39 \%$ to $92.3 \%$, with the majority of studies reporting less than $60 \%$ usage. ${ }^{15}$ Our results are consistent with these findings and serve to underscore the degree to which high-risk atrial fibrillation remains undertreated in actual clinical practice.

This study is limited by its retrospective design, restriction to a single health-care system, and its reliance on the completeness and accuracy of the data encoded within the EMR. Warfarin exposure was inferred using physician prescription history and INR values. Whether or not a patient actually filled a prescription was unknown, and it is likely that overall we overestimated exposure time. It is also likely that some patients were comanaged with external specialists. INRs obtained by these external practices would not always be captured in the EMR, resulting in gaps between measurements later classified as unknown TTR. The large proportion of unknown TTR limited its use in analyzing stroke and bleeding outcomes and as a result we used the frequency of warfarin interruptions as a surrogate for quality of anticoagulation. We did not, however, investigate the causes for these interruptions, and when TTR was known there was no significant difference in TTR $\geq 60 \%$ between groups. In addition, the limitation of this study to a single hospital system, despite its regional dominance, almost certainly underestimates the rate of stroke and bleeding events. 
Given our limitations in measuring TTR, however, it is likely that the frequency of interruptions better reflects the overall quality of anticoagulation in this population, thus explaining its apparent impact on stroke risk.

In conclusion, this study supports previous findings that warfarin in actual practice is underutilized in a substantial portion of eligible atrial fibrillation patients. Furthermore, when warfarin is used, it is continued in less than half of these patients for less than half of their follow-up time. In addition, prolonged interruptions in anticoagulation are common in this population, and multiple interruptions are associated with over twice the risk of stroke when compared to those treated continuously. These findings highlight the substantial unmet need for adequate and consistent anticoagulation in this population.

\section{Acknowledgments}

This research was supported by a grant from Bristol-Myers Squibb and Pfizer. This work was presented at the annual meeting of the AHA Quality of Care and Outcomes Research in Cardiovascular Disease and Stroke 2011, Washington, DC, May 14, 2011.

\section{Disclosure}

Ewen, Zhang, Kolm, and Weintraub have received research funding from Bristol-Myers Squibb, Pfizer, and Sanofi. Simon is an employee of Bristol-Myers Squibb. Liu is an employee of Pfizer.

\section{References}

1. Chugh SS, Blackshear JL, Shen WK, Hammill SC, Gersh BJ. Epidemiology and natural history of atrial fibrillation: clinical implications. J Am Coll Cardiol. 2001;37(2):371-378.

2. Miyasaka Y, Barnes ME, Gersh BJ, et al. Secular trends in incidence of atrial fibrillation in Olmsted County, Minnesota, 1980 to 2000, and implications on the projections for future prevalence. Circulation. 2006;114(2):119-125.

3. Wolf PA, Abbott RD, Kannel WB. Atrial fibrillation as an independent risk factor for stroke: the Framingham Study. Stroke. 1991;22(8):983-988.

4. Wang TJ, Larson MG, Levy D, et al. Temporal relations of atrial fibrillation and congestive heart failure and their joint influence on mortality: the Framingham Heart Study. Circulation. 2003;107(23): 2920-2925.

5. Benjamin EJ, Wolf PA, D’Agostino RB, Silbershatz H, Kannel WB, Levy D. Impact of atrial fibrillation on the risk of death: the Framingham Heart Study. Circulation. 1998;98(10):946-952.

6. Petersen P, Boysen G, Godtfredsen J, Andersen ED, Andersen B. Placebo-controlled, randomised trial of warfarin and aspirin for prevention of thromboembolic complications in chronic atrial fibrillation. The Copenhagen AFASAK study. Lancet. 1989;1(8631):175-179.

7. [No authors listed]. Stroke Prevention in Atrial Fibrillation Study. Final results. Circulation. 1991;84(2):527-539.

8. [No authors listed]. The effect of low-dose warfarin on the risk of stroke in patients with nonrheumatic atrial fibrillation. The Boston Area Anticoagulation Trial for Atrial Fibrillation Investigators. NEngl J Med. 1990;323(22):1505-1511.
9. Ezekowitz MD, Bridgers SL, James KE, et al. Warfarin in the prevention of stroke associated with nonrheumatic atrial fibrillation. Veterans Affairs Stroke Prevention in Nonrheumatic Atrial Fibrillation Investigators. N Engl J Med. 1992;327(20):1406-1412.

10. [No authors listed]. Risk factors for stroke and efficacy of antithrombotic therapy in atrial fibrillation. Analysis of pooled data from five randomized controlled trials. Arch Intern Med. 1994;154(13):1449-1457.

11. Fuster V, Ryden LE, Cannom DS, et al. ACC/AHA/ESC 2006 Guidelines for the Management of Patients with Atrial Fibrillation: a report of the American College of Cardiology/American Heart Association Task Force on Practice Guidelines and the European Society of Cardiology Committee for Practice Guidelines (Writing Committee to Revise the 2001 Guidelines for the Management of Patients With Atrial Fibrillation): developed in collaboration with the European Heart Rhythm Association and the Heart Rhythm Society. Circulation. 2006;114(7):e257-e354.

12. Hylek EM, Skates SJ, Sheehan MA, Singer DE. An analysis of the lowest effective intensity of prophylactic anticoagulation for patients with nonrheumatic atrial fibrillation. $N$ Engl J Med. 1996;335(8):540-546.

13. Hylek EM, Singer DE. Risk factors for intracranial hemorrhage in outpatients taking warfarin. Ann Intern Med. 1994;120(11):897-902.

14. Hylek EM, Go AS, Chang Y, et al. Effect of intensity of oral anticoagulation on stroke severity and mortality in atrial fibrillation. N Engl J Med. 2003;349(11):1019-1026.

15. Ogilvie IM, Newton N, Welner SA, Cowell W, Lip GY. Underuse of oral anticoagulants in atrial fibrillation: a systematic review. Am J Med. 2010;123(7):638-645.

16. Boulanger L, Kim J, Friedman M, Hauch O, Foster T, Menzin J. Patterns of use of antithrombotic therapy and quality of anticoagulation among patients with non-valvular atrial fibrillation in clinical practice. Int $J$ Clin Pract. 2006;60(3):258-264.

17. Chiquette E, Amato MG, Bussey HI. Comparison of an anticoagulation clinic with usual medical care: anticoagulation control, patient outcomes, and health care costs. Arch Intern Med. 1998;158(15):1641-1647.

18. Matchar DB, Samsa GP, Cohen SJ, Oddone EZ, Jurgelski AE. Improving the quality of anticoagulation of patients with atrial fibrillation in managed care organizations: results of the managing anticoagulation services trial. Am J Med. 2002;113(1):42-51.

19. Samsa GP, Matchar DB, Goldstein LB, et al. Quality of anticoagulation management among patients with atrial fibrillation: results of a review of medical records from 2 communities. Arch Intern Med. 2000;160(7):967-973.

20. McCormick D, Gurwitz JH, Goldberg RJ, et al. Prevalence and quality of warfarin use for patients with atrial fibrillation in the long-term care setting. Arch Intern Med. 2001;161(20):2458-2463.

21. Nichol MB, Knight TK, Dow T, et al. Quality of anticoagulation monitoring in nonvalvular atrial fibrillation patients: comparison of anticoagulation clinic versus usual care. Ann Pharmacother. 2008;42(1):62-70.

22. Shen AY, Yao JF, Brar SS, Jorgensen MB, Chen W. Racial/ethnic differences in the risk of intracranial hemorrhage among patients with atrial fibrillation. J Am Coll Cardiol. 2007;50(4):309-315.

23. Fang MC, Go AS, Chang Y, et al. Warfarin discontinuation after starting warfarin for atrial fibrillation. Circ Cardiovasc Qual Outcomes. 2010;3(6):624-631.

24. Baker WL, Cios DA, Sander SD, Coleman CI. Meta-analysis to assess the quality of warfarin control in atrial fibrillation patients in the United States. J Manag Care Pharm. 2009;15(3):244-252.

25. Gage BF, Waterman AD, Shannon W, Boechler M, Rich MW, Radford MJ. Validation of clinical classification schemes for predicting stroke: results from the National Registry of Atrial Fibrillation. JAMA. 2001;285(22):2864-2870.

26. Rosendaal FR, Cannegieter SC, van der Meer FJ, Briet E. A method to determine the optimal intensity of oral anticoagulant therapy. Thromb Haemost. 1993;69(3):236-239.

27. Kaplan EL, Meier P. Nonparametric estimation from incomplete observations. J Am Stat Assoc. 1958;53:457-481. 
28. Essebag V, Platt RW, Abrahamowicz M, Pilote L. Comparison of nested case-control and survival analysis methodologies for analysis of time-dependent exposure. BMC Med Res Methodol. 2005;5(1):5.

29. Essebag V, Genest J Jr, Suissa S, Pilote L. The nested case-control study in cardiology. Am Heart J. 2003;146(4):581-590.

30. Suissa $\mathrm{S}$. Novel approaches to pharmacoepidemiology study design and statistical analysis. In: Strom B, editor. Pharmacoepidemiology. Chichester: John Wiley and Sons; 2005:811-829.

31. Shalev V, Rogowski O, Shimron O, et al. The interval between prothrombin time tests and the quality of oral anticoagulants treatment in patients with chronic atrial fibrillation. Thromb Res. 2007;120(2):201-206.
32. Gandolfo C, Balestrino M, Burrone A, Del Sette M, Finocchi C. Stroke due to atrial fibrillation and the attitude to prescribing anticoagulant prevention in Italy. A prospective study of a consecutive stroke population admitted to a comprehensive stroke unit. J Neurol. 2008;255(6):796-802.

33. Reynolds MR, Shah J, Essebag V, et al. Patterns and predictors of warfarin use in patients with new-onset atrial fibrillation from the FRACTAL Registry. Am J Cardiol. 2006;97(4):538-543.

34. De Schryver EL, van Gijn J, Kappelle LJ, Koudstaal PJ, Algra A. Non-adherence to aspirin or oral anticoagulants in secondary prevention after ischaemic stroke. J Neurol. 2005;252(11):1316-1321. 


\section{Appendix}

Appendix I Exclusion criteria data definitions

\begin{tabular}{ll}
\hline Criteria & Definition \\
\hline Transient perioperative & An outpatient diagnosis of AF occurring within 30 days of an inpatient diagnosis of coronary artery bypass \\
atrial fibrillation & surgery (ICD-9 codes 36.10 to 36.19 ), pericardial surgery (ICD-9 codes 37.10 to $37.12,37.3$ I to 37.33, or \\
& $37.40)$, or structural cardiac repair (ICD-9 codes 35.00 to $35.04,35.3$ to $35.39,35.4 I$ to $35.42,35.50$ to \\
& $35.56,35.60$ to 35.63, or 35.70 to 35.73$)$ \\
Mitral or aortic valvular repair & An inpatient or office diagnosis of mitral stenosis or prosthetic heart valve (ICD-9 codes $394.0,394.2,396.0$, \\
or replacement & $396 . I, 396.8$, V43.3, or V42.2) or mitral or aortic valve repair or replacement (ICD-9 codes 35.10 to 35.14 \\
Hyperthyroidism & or 35.20 to 35.28$)$ \\
& Any of the following within I2 months before the index date: an inpatient or outpatient diagnosis of
\end{tabular}

Abbreviations: AF, atrial fibrillation; ICD-9, International Classification of Diseases, Ninth Revision.

Appendix 2 Potential barriers to warfarin use

\begin{tabular}{|c|c|c|}
\hline Variable & Definition & Source \\
\hline Prior GI/GU & Recent Gl or GU hemorrhage recorded in the problem list or on hospital & Office EMR \\
\hline hemorrhage & $\begin{array}{l}\text { discharge (ICD-9 codes 578.x, 531.0, 531.2, 531.4, 531.6, 532.0, 532.2, 532.4, } \\
532.6,533.0,533.2,533.4,533.6,534.0,534.2,534.4,534.6,535 . x I, 530.82, \\
456.0,456.2,569.3,596.7)\end{array}$ & Hospital discharges \\
\hline Ethanol abuse & $\begin{array}{l}\text { A history of ethanol abuse or related diagnoses (ICD-9 codes } 291.0-2,298.81 \text {, } \\
303 . x, 305.0 x, 571.0-3,535.3) \text { prior to the index date recorded in the problem } \\
\text { list or indicated in office notes on CAGE assessment or social history }\end{array}$ & $\begin{array}{l}\text { Office EMR } \\
\text { Hospital discharges }\end{array}$ \\
\hline Predisposition & ICD-9 codes recorded in the problem list or on hospital discharge & Office EMR \\
\hline to falls & of 290.x-294.x, 33।.0, 33।.I, 333.4, 345.x, 347, 458.0, 780.2, 780.3, E880-888 & Hospital discharges \\
\hline Perceived barriers & ICD-9 codes recorded in the problem list or on hospital discharge & Office EMR \\
\hline to compliance & of $295 . x-298 . x, V 60.0-V 60.4, V I 5.8 I$ & Hospital discharges \\
\hline \multirow[t]{3}{*}{ Cirrhosis/hepatitis } & ICD-9 codes recorded in the problem list or on hospital discharge & Office EMR \\
\hline & of $070.2-070.9,570,57$ I.x, 572.2, 572.3, 572.4, 572.8, 573.x or an & Hospital discharges \\
\hline & elevated aspartate transaminase or alanine transaminase value $(\geq 2 \times$ normal) & Lab database \\
\hline \multirow[t]{5}{*}{ Renal insufficiency } & A diagnosis of renal disease (ICD-9 codes 042.9, 285.2, 403.x, 404.x, 572.4, 582.x, & Office EMR \\
\hline & 583.x, 584.5-584.9, 585.x, 753.13, 799.9, 866.0) entered by a physician prior & Hospital discharges \\
\hline & to the index in the problem list or evidence of chronic kidney disease & Lab database \\
\hline & stage 4 or 5 by estimated glomerular filtration rate & \\
\hline & (calculated by Modification of Diet in Renal Disease equation) & \\
\hline
\end{tabular}

Abbreviations: GI, gastrointestinal; GU, genitourinary; EMR, electronic medical record; ICD-9, International Classification of Diseases, Ninth Revision. 
Appendix 3 Predictors of stroke and their definitions

\begin{tabular}{|c|c|c|}
\hline Variable & Definition & Source \\
\hline Age & Calculated age of patient at time of the index visit using index date and date of birth & Office EMR \\
\hline Age $\geq 75$ & $\begin{array}{l}\text { Age at index date expressed as a dichotomous variable }(I=\text { age } \geq 75 \text { years, } \\
0=\text { age }<75 \text { years }\end{array}$ & Office EMR \\
\hline Congestive & A diagnosis of heart failure recorded prior to or on the index date in the & Office EMR \\
\hline heart failure & $\begin{array}{l}\text { office-record problem list or evidence of a hospital admission with a principal } \\
\text { diagnosis of heart failure (ICD-9 codes } 428 . x)\end{array}$ & Hospital discharges \\
\hline Hypertension & $\begin{array}{l}\text { A diagnosis of hypertension prior to the index date entered by a physician in the } \\
\text { office-record problem list or at least two serial blood pressure measures }>140 / 90\end{array}$ & Office EMR \\
\hline Diabetes & $\begin{array}{l}\text { A diagnosis of diabetes mellitus (ICD-9-CM codes } 250 . x x \text { ) prior to the index entered } \\
\text { by a physician in the office-record problem list or an active oral hypoglycemic medication } \\
\text { or insulin on the office medication list }\end{array}$ & Office EMR \\
\hline $\begin{array}{l}\text { Coronary heart } \\
\text { disease }\end{array}$ & $\begin{array}{l}\text { A diagnosis entered by a physician in the problem list or a hospital discharge } \\
\text { with a principal ICD-9 code of } 410,4 I I, 4 I 3-414,429.2 \text { prior to index }\end{array}$ & $\begin{array}{l}\text { Office EMR } \\
\text { Hospital discharges }\end{array}$ \\
\hline $\begin{array}{l}\text { Stroke or transient } \\
\text { ischemic attack }\end{array}$ & $\begin{array}{l}\text { A hospital discharge with a principal ICD-9 code of } 430,43 \text { I, } 433-436 \text { prior to index. } \\
\text { Hospitalizations with ICD-9 codes } 433 . x-436 . x \text { lasting less than } 48 \text { hours } \\
\text { and associated carotid endarterectomy will be excluded }\end{array}$ & Hospital discharges \\
\hline $\mathrm{CHADS}_{2}$ & $\begin{array}{l}\text { A stroke risk score using five of the above variables. The total score is the sum } \\
\text { of the following factors: congestive heart failure }=\mathrm{I} \text {, hypertension }=\mathrm{I} \text {, } \\
\text { age } \geq 75 \text { years }=\mathrm{I} \text {, diabetes mellitus }=\mathrm{I} \text {, and prior stroke or transient ischemic attack = } 2\end{array}$ & $\begin{array}{l}\text { Office EMR } \\
\text { Hospital discharges }\end{array}$ \\
\hline
\end{tabular}

Abbreviations: EMR, electronic medical record; ICD-9, International Classification of Diseases, Ninth Revision.

\section{Publish your work in this journal}

Vascular Health and Risk Management is an international, peerreviewed journal of therapeutics and risk management, focusing on concise rapid reporting of clinical studies on the processes involved in the maintenance of vascular health; the monitoring, prevention and treatment of vascular disease and its sequelae; and the involvement of metabolic disorders, particularly diabetes. This journal is indexed on PubMed Central and MedLine. The manuscript management system is completely online and includes a very quick and fair peer-review system, which is all easy to use. Visit http://www.dovepress.com/ testimonials.php to read real quotes from published authors. 